\title{
Anabases
}

ANABASES Traditions et réceptions de l'Antiquité

16 | 2012

Varia

\section{Une nouvelle rubrique pour Anabases : relire les classiques des Sciences de l'Antiquité}

Pascal Payen

\section{(2) OpenEdition}

1 Journals

Édition électronique

URL : http://journals.openedition.org/anabases/3985

DOI : 10.4000/anabases.3985

ISSN : 2256-9421

Éditeur

E.R.A.S.M.E.

Édition imprimée

Date de publication : 1 octobre 2012

Pagination : 235-236

ISSN : 1774-4296

\section{Référence électronique}

Pascal Payen, « Une nouvelle rubrique pour Anabases : relire les classiques des Sciences de

I'Antiquité », Anabases [En ligne], 16 | 2012, mis en ligne le 01 octobre 2015, consulté le 21 octobre 2019. URL : http://journals.openedition.org/anabases/3985 ; DOI : 10.4000/anabases.3985

(c) Anabases 
Anabases 16 (2012), p. 235-236.

\section{Une nouvelle rubrique pour Anabases : relire les classiques des Sciences de l'Antiquité}

Pascal Payen

$A_{\text {NABASES s'enrichit d'une nouvelle rubrique. }}$

La revue a porté, depuis ses débuts, un regard réflexif sur l'histoire des disciplines et des savoirs consacrés à l'Antiquité. Dans quels contextes se sont-ils constitués ? Quelles institutions les ont accueillis et ont structuré, infléchi, enrichi leur développement ? Quels acteurs, qu'ils soient issus du sérail ou non, ont suscité, par leurs découvertes, des changements décisifs ou ont permis, par un labeur de longue durée, qu'une tradition d'étude nouvelle se forme, qu'un instrument de travail tel qu'un corpus documentaire soit mis à la disposition de tous ? La connaissance de Antiquité repose sur un ensemble de savoirs qui non seulement ont leur histoire - c'est là une banalité -, mais dont l'histoire même a configuré l'Antiquité en tant qu'objet d'étude. La manière dont les textes auxquels les savants et les amateurs se reportent pour accéder à l'Antiquité sont édités, traduits, découpés, annotés n'est pas sans conséquence. Elle modifie, sans que nous nous en rendions compte le plus souvent, la nature même des connaissances que nous en tirons et des analyses que la communauté des chercheurs en déduit pour mieux comprendre des institutions politiques, des pratiques sociales, des croyances, des genres littéraires, des traditions philosophiques. Ce qui est ici suggéré des sources textuelles vaut aussi pour les autres corpus, épigraphiques, archéologiques, iconographiques, plastiques. Tous ont une histoire qui remonte le plus souvent, mais pas toujours, à la première moitié du XIX ${ }^{e}$ siècle. Alors se constitue, au sein de l'université allemande, puis européenne, la "Science de l'Antiquité ", Altertumswissenschaft ou Altertumskunde, qu'il est de coutume de rendre par un pluriel pour mieux mettre en lumière la complémentarité de nombreux savoirs spécialisés consacrés à l'Antiquité, qu'enrichissent continument les apports des sciences historiques et sociales. 
Dans le domaine de l'Antiquité, en effet, les enrichissements proviennent de découvertes qui associent une manière nouvelle de recouper les documents, de croiser les sources, et la réflexion issue des questions du temps présent. Les sciences de l'Antiquité sont, redisons-le, des sciences historiques et sociales. Elles progressent ou, si l'on préfere, elles s'élaborent, elles se reconfigurent par les publications des spécialistes : littéraires, historiens, épigraphistes, et tous ceux qui appartiennent à d'autres provinces de la carte des savoirs, toujours mouvante dans ses partages et ses frontières. Parmi ces publications, certaines font date dans l'histoire de la science antiquisante et, souvent aussi, dans l'histoire des sciences humaines. Ce sont ces études, ces articles, ces analyses, devenues souvent peu accessibles, que nous nous proposons de publier à nouveau, en demandant à un spécialiste de les mettre en perspective par une présentation de nature historiographique. Le sens que revêt le passé pour le présent s'est construit, pour une part importante, dans l'histoire des savoirs consacrés à ce lieu d'échanges entre les sciences humaines qu'est l'Antiquité. 